\title{
Differential expression of mycobacterial antigen MPT64, apoptosis and inflammatory markers in multinucleated giant cells and epithelioid cells in granulomas caused by Mycobacterium tuberculosis
}

\author{
Tehmina Mustafa • Harald G. Wiker • Odd Mørkve • \\ Lisbet Sviland
}

Received: 4 October 2007 /Revised: 20 November 2007 / Accepted: 28 December 2007 / Published online: 12 February 2008

(C) The Author(s) 2008

\begin{abstract}
The development of granulomas is a major histopathological feature of tuberculosis. Very little information is available concerning the physiology and functions of different cell types in the tuberculous granulomas. The aim of this study was to compare the epithelioid cells (ECs) and multinucleated giant cells (MGCs) in the granulomas caused by Mycobacterium tuberculosis complex organisms. Lymph node biopsies from 30 cases of lymphadenitis were studied for expression of the secreted mycobacterial protein MPT64, caspase 3 as a marker of apoptosis, apoptosis-related proteins (Fas Ligand, Fas and Bax) and inflammatory cytokines (interleukin-10, transforming growth factor- $\beta$ (TGF- $\beta$ ), tumour necrosis factor- $\alpha$ and interferon- $\gamma$ ) by immunohistochemistry. MGCs
\end{abstract}

T. Mustafa $\cdot$ H. G. Wiker

Section for Microbiology and Immunology, The Gade Institute, University of Bergen,

Bergen, Norway

\section{H. G. Wiker}

Department of Microbiology and Immunology,

Haukeland University Hospital,

Bergen, Norway

O. Mørkve $\cdot$ L. Sviland

Centre for International Health, University of Bergen,

Bergen, Norway

L. Sviland

Department of Pathology, Haukeland University Hospital,

Bergen, Norway

T. Mustafa $(\bowtie)$

Section for Microbiology and Immunology, The Gade Institute, Armauer Hansens Building, Haukeland University Hospital, Bergen, Norway

e-mail: tehmina.mustafa@gades.uib.no more often contained $M$. tuberculosis secretory antigen MPT64 $(p<0.001)$ and expressed more TGF- $\beta(p=0.004)$ than ECs. The total number of apoptotic MGCs was higher than the number of apoptotic ECs $(p=0.04)$. Interestingly, there was a significant negative correlation between apoptosis and MPT64 expression in MGCs $(r=-0.569, p=0.003)$, but not in ECs, implying that the heavy antigen load would lead to inhibition of apoptosis in these cells. When compared with ECs, higher percentage of MGCs expressed Fas Ligand and Fas $(p<0.004)$. The role of MGCs may thus be different from surrounding ECs and these cells by virtue of higher mycobacterial antigen load, more TGF- $\beta$ and reduced apoptosis may contribute towards persistence of infection.

Keywords Epithelioid cells · Multinucleated giant cells · Granulomas · MPT64 · Apoptosis · Cytokines · Tuberculosis

\section{Introduction}

The development of granulomas in tuberculosis (TB) is an expression of acquired specific immune response in the host and is the main histopathological feature of tuberculosis. These granulomas are thought to contain the infection in a localised area, preventing bacterial spread to surrounding healthy tissues and to other organs $[30,31]$. In humans, granuloma formation is essential for control of mycobacterial infections, as shown in children where a lack of granulomatous response is associated with unfavourable clinical outcome [7]. Immuno-deficient individuals without interferon (IFN)- $\gamma$-induced responses fail to develop granulomatous structures and subsequently die of mycobacterial 
infection [3]. Paradoxically, granulomas are also responsible for the typical immunopathology caused by these infections.

Interleukin (IL)-10, transforming growth factor (TGF)- $\beta$, tumour necrosis factor (TNF)- $\alpha$ and IFN- $\gamma$ are produced locally within tuberculous granulomas. In various experimental systems, it has been shown that TNF- $\alpha$ is associated with activation of macrophages [8] and enhances the bactericidal activity of monocytes and macrophages together with IFN- $\gamma$ [9]. Both these cytokines are responsible for granuloma formation $[5,16]$. On the other hand, IL-10 and TGF- $\beta$ suppress the anti-mycobacterial immune responses and inhibit macrophage functions resulting in enhanced intracellular growth of bacteria $[4,13,21,34]$. These cytokines by virtue of their anti-inflammatory properties play a role in limiting the excessive immune response, thus limiting tissue destruction. An optimal balance between various cytokines would lead to an effective protective immune response. Mycobacterium tuberculosis has evolved strategies to evade killing by the host response and this can affect the pattern of cytokine secretion in the granulomas. Pathogenic mycobacteria are shown to inhibit the apoptosis of the infected cells [15] by influencing the secretion of apoptosis-related proteins Fas, Fas Ligand (FasL) [22-24], Bcl2 and Bax [20], which leads to the bacterial persistence.

In vitro studies have shown the dynamics of granuloma formation. M. tuberculosis multiplies within macrophages and monocytes and the production of cytokines and chemokines by these infected macrophages induces the recruitment of macrophages, lymphocytes and dendritic cells at the infectious site. This cellular accumulation results in granuloma formation. Within granulomas, macrophages differentiate into epithelioid cells (ECs) and/or fuse to form multinucleated giant cells (MGCs), also called Langhans giant cells [11, 32]. Very little information is available concerning the physiology of granuloma-specific cell types such as ECs and MGCs. Are these two cell types different in their expression of various inflammatory markers and what role do they play in the host immunity? We have recently shown that there is a negative correlation between apoptotic markers and MPT64 expression in tuberculous granulomas [28]. It has been postulated that granulomas are responsible for the persistence of bacilli, but which cell types in the granulomas contribute towards this is not known.

The specific aim of this study was to compare the ECs and MGCs in the lesions caused by M. tuberculosis with respect to the expression of secreted mycobacterial protein MPT64 as a marker for mycobacterial infection, expression of caspase 3 as a marker of apoptosis, apoptosis-related proteins (FasL, Fas and Bax) and inflammatory cytokines (IL-10, TGF- $\beta$, TNF- $\alpha$ and IFN- $\gamma$ ).

\section{Material and methods}

Lymph node biopsies from 30 cases of tuberculous lymphadenitis were studied. Seventeen cases were obtained from the archives of Department of Pathology, Haukeland University Hospital, Norway. Thirteen cases were from patients diagnosed with mycobacterial lymphadenitis in an epidemiological study from rural Tanzania [19]. All these cases were confirmed to be caused by $M$. tuberculosis complex organisms based on the polymerase chain reaction done for amplification of IS6110 as described earlier [27]. All the cases were studied for the expression of mycobacterial antigen, apoptosis and all the proteins except Bax which was studied in 13 Tanzanian cases only. Ethical clearance was obtained from the Medical Research Coordinating Committee in Tanzania and the regional ethical committee in Norway. All participants from Tanzania gave verbal consent to the study.

\section{Histology and immunohistochemistry}

Parallel 5- $\mu \mathrm{m}$-thick sections from each specimen were stained with haematoxylin and eosin, and immunostaining was done as described previously [25]. A kit (EnVision+ System-HRP) was used for immunostaining (DakoCytomation Denmark A/S, Glostrup, Denmark). Briefly, after deparaffinisation and rehydration, the sections were exposed to microwave antigen retrieval using citrate buffer $\mathrm{pH} 6.0$ at $750 \mathrm{~W}$ for $10 \mathrm{~min}$ and at $350 \mathrm{~W}$ for $15 \mathrm{~min}$. The sections were cooled for $20 \mathrm{~min}$ at room temperature and then incubated with $\mathrm{H}_{2} \mathrm{O}_{2}$ solution for 5 min. Primary antibodies were then applied to the sections for $45 \mathrm{~min}$ followed by incubation for $40 \mathrm{~min}$ with anti-rabbit or anti-mouse immunoglobulin conjugated with dextran polymer and horseradish peroxidase. The visualisation was with 3-amino9-ethylcarbazol containing $\mathrm{H}_{2} \mathrm{O}_{2}$ (for cytokines and caspase 3) or diaminobenzidine for $10 \mathrm{~min}$ (for apoptosis-related proteins).

The following primary antibodies were used: MPT64 was detected using in-house-raised polyclonal rabbit antibodies [27]. Apoptotic cells were detected by caspase 3 staining (R\&D Systems, Abingdon, Oxon, UK). IL-10, TNF- $\alpha$ and IFN- $\gamma$ were detected with antibodies from ImmunoTools, Friesoythe, Germany, TGF- $\beta$ with antibodies from Santa Cruz Biotechnology, Santa Cruz, CA, USA. Apoptosis-related protein FasL with antibodies from Alexis Biochemicals, San Diego, CA, USA, Fas, Bax and Bcl-2 with antibodies from Santa Cruz Biotechnology, Santa Cruz, California, USA. All of the antibodies were mouse monoclonal antibodies except anti-TGF- $\beta$, and anticaspase-3 which were rabbit polyclonal antibodies as described previously [25]. 
Evaluation of histology, immunostaining and statistical analysis

The percentage of stained ECs was calculated by counting stained cells and the total number of nucleated cells in two to three areas from each biopsy, using a $\times 40$ ocular fitted with a $10 \times 10-\mathrm{mm}$ grid. All the stained cells, irrespective of staining intensity, were counted. On average, 334 nucleated cells were present in one field-grid. For MGCs, the whole section was studied and all the MGCs were counted. Data were presented as a percentage of the stained MGCs. The number of MGCs varied in the biopsies ranging from 2 to 42 (median=15) MGCs. Non-parametric Wilcoxon signedrank sum test for related samples was used for comparison of ECs and MGCs. Linear regression was performed to determine the relationship between the number of apoptotic cells and cells containing mycobacterial antigen. Bivariate correlations between number of cells stained for various proteins was determined by Spearman's rank correlations. $p$ values less than 0.05 were considered as significant.

\section{Results}

\section{Morphology}

All the biopsies had necrotic granulomas. In 11 cases, there were additional non-necrotic granulomas. The morphology of MGCs varied. Some cells were relatively small with four to five nuclei in the centre of the cell, while others were large cells with many nuclei forming a ring in the cytoplasm. Both types of cells could be present in the same biopsy.
Fig. 1 a-b Percentage of epithelioid cells (ECs) and multinucleated giant cells $(M G C s)$ expressing MPT64 antigen (a), and caspase 3 for apoptotic cells (b) detected by immunohistochemical staining in the lymphadenitis granulomas caused by M. tuberculosis $(n=30)$. The median, 25th and 75th percentiles and minimum and maximum values are shown. The marks filled circle indicate the outliers. The statistically significant results are marked with $p$ values. c-d Linear regression was performed to determine the relationship between apoptotic ECs and the MPT64-antigencontaining ECs (c), and apoptotic MGCs and MPT64-antigen-containing MGCs (d) among the tuberculous granulomas. There was a significant negative correlation between apoptotic MGCs and MPT64-antigen-containing MGCs a



C



b

d
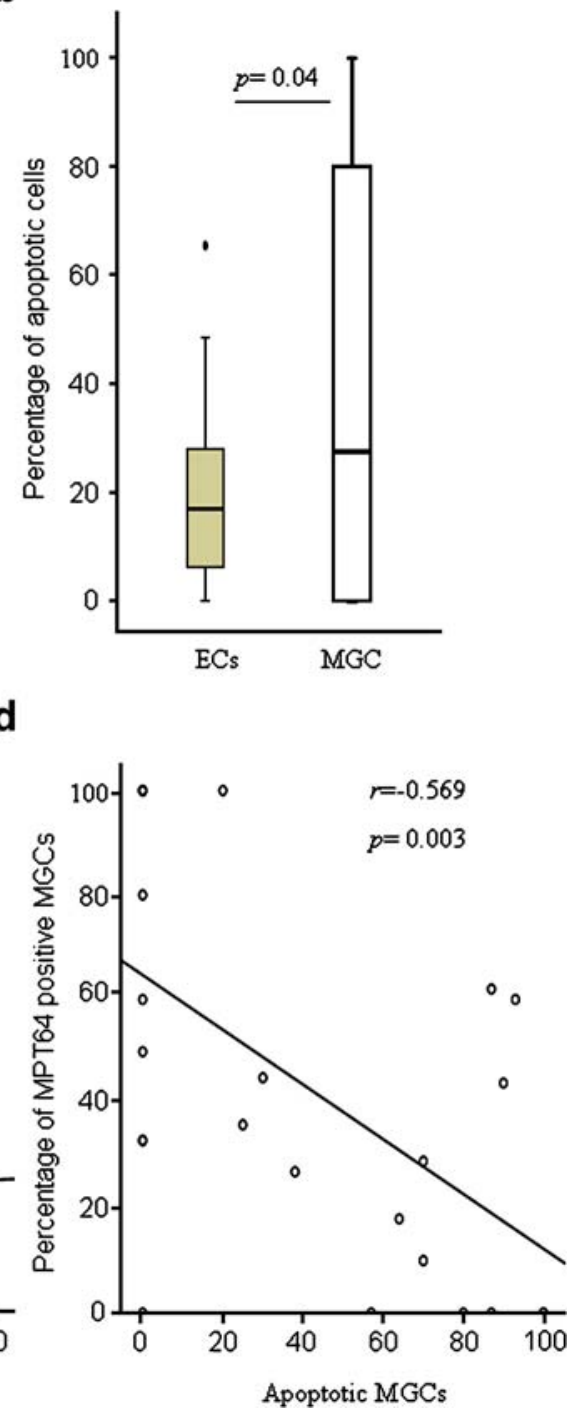
MPT64 expressing MGCs correlate negatively with apoptotic MGCs

MPT64 was expressed in the ECs and MGCs in the granulomas. Figure 1a shows the number of ECs and MGCs expressing MPT64 antigen. A higher proportion of MGCs (median=33\%) expressed MPT64 antigen as compared to the ECs (median=2.1\%, $<<0.001$ ). The intensity of staining in ECs and MGCs varied from weak to strong, indicating variation in the amount of antigen present in individual cells. Figure 2 shows granuloma cells with strong expression of MPT64 antigen.

Expression of caspase 3 was used to detect the apoptotic cells. Both ECs and MGCs in the granulomas expressed caspase 3 as shown in Fig. 2. Figure 1b shows the number of ECs and MGCs expressing this protein. The numbers of apoptotic ECs (median=17\%) were lower than the apoptotic MGCs (median=27.5\%, $p=0.04$ ). Interestingly, there was a significant negative correlation between the apoptotic
MGCs and the MPT64 expressing MGCs $(r=-0.569, p=$ 0.003 ), while no significant correlation was found between apoptotic ECs and MPT64 expressing ECs (Fig. 1c-d), implying that the heavy antigen load would lead to inhibition of apoptosis in these cells.

\section{MGCs express more FasL and Fas than ECs}

Both the ECs and MGCs expressed FasL, Fas and Bax (Fig. 2). Figure 3a shows the number of these cells expressing the proteins. When compared with ECs, higher percentage of MGCs expressed FasL (median; $\mathrm{EC}=23.3 \%$, $\mathrm{MGC}=45.7 \%, p=0.008$ ) and Fas (median; $\mathrm{EC}=15.3 \%$, $\mathrm{MGC}=44 \%, p=0.005)$. Table 1 shows the correlation between the numbers of ECs and MGCs expressing different proteins. The relationship of these proteins was different between the ECs and MGCs. FasL-expressing ECs correlated positively with Fas- $(p<0.001)$ and Baxexpressing $(p<0.05) \mathrm{ECs}$, and Fas-expressing ECs correlated
Fig. 2 Lymph node tissues showing the staining pattern of epithelioid cells and multinucleated giant cells in the tuberculous granulomas for mycobacterial secretory antigen MPT64, caspase 3 for detection of apoptotic cells, apoptosis-related proteins and cytokines, as detected by immunohistochemical staining
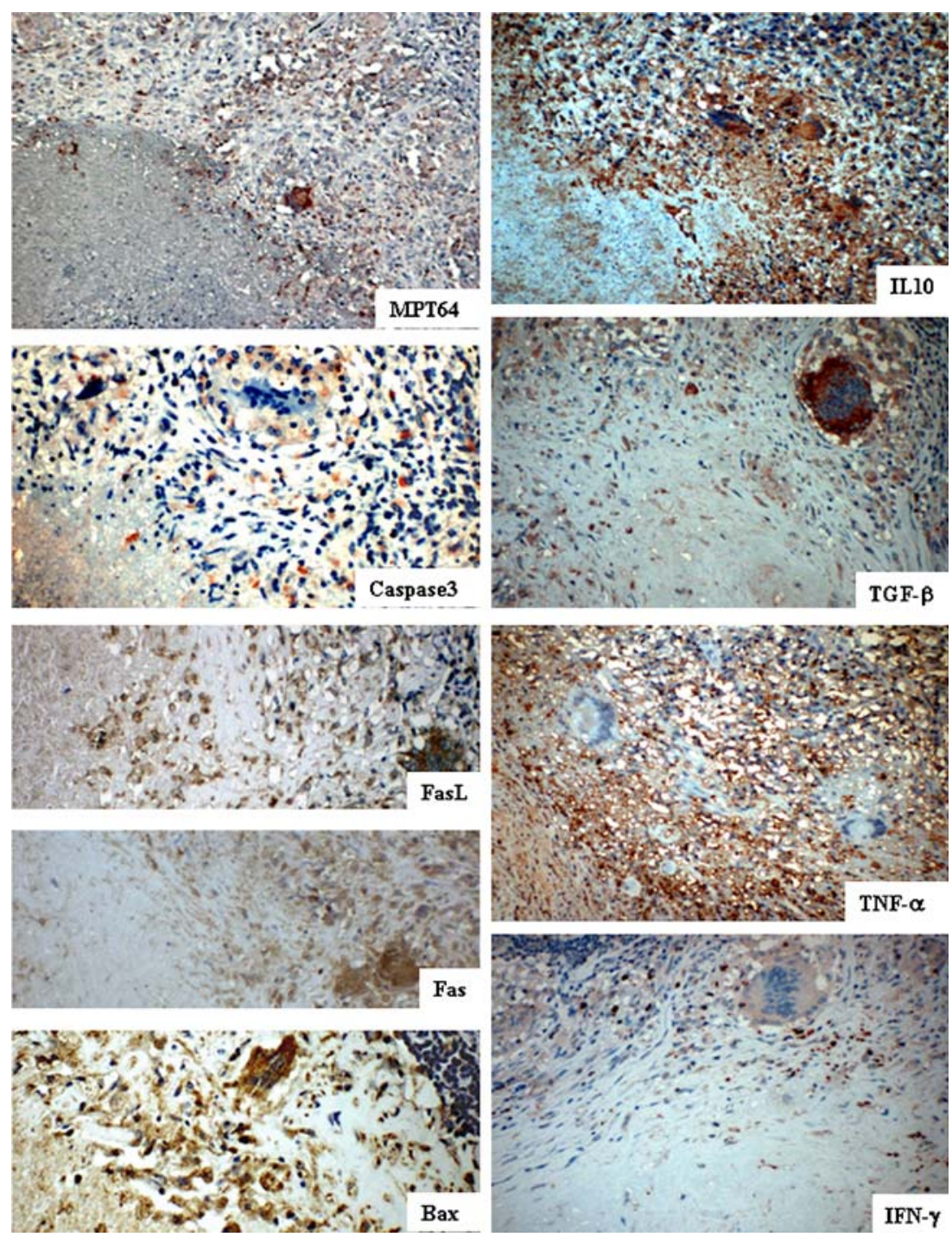
a



b

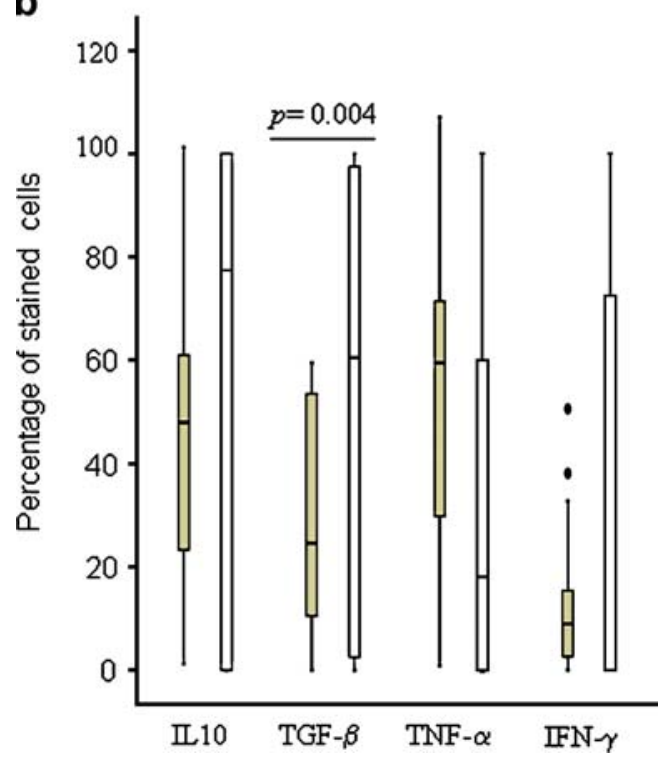

Fig. 3 Percentage of epithelioid cells $\square$ and multinucleated giant cells $\square$ expressing apoptosis-related proteins (a) and cytokines (b) in the lymphadenitis granulomas caused by M. tuberculosis, detected by immunohistochemical staining. The median, 25 th and 75 th percentiles and minimum and maximum values are shown. The marks filled circles indicate the outliers. The statistically significant results are marked with $p$ values

positively with Bax-expressing ECs $(p<0.05)$. While among MGCs, FasL-expressing MGCs correlated positively with TGF- $\beta$ - and IFN- $\gamma$-expressing MGCs, and Fas-expressing MGCs correlated positively with IL-10-expressing MGCs $(p<0.05)$. Fas- and Bax-expressing ECs and MGCs correlated positively $(p<0.001)$.

MGCs express more TGF- $\beta$ than the ECs

Among the pro- and anti-inflammatory cytokines, ECs and MGCs expressed IL-10, TGF- $\beta$, TNF- $\alpha$ and IFN- $\gamma$
(Fig. 2). Figure $3 \mathrm{~b}$ shows the numbers of cells expressing these cytokines. Higher number of MGCs expressed TGF- $\beta$ as compared with $\mathrm{ECs}$ (median; $\mathrm{MGC}=60.5 \%, \mathrm{EC}=24.5 \%$, $p=0.004$ ), while there was no statistically significant difference between the number of two cell types expressing IL-10, TNF- $\alpha$ or IFN- $\gamma$. The intensity of staining of IFN- $\gamma$ was, however, stronger in the ECs than in the MGCs (Fig. 2), but the cell counts represent all stained cells irrespective of staining intensity. The number of TGF- $\beta$ expressing MGCs were higher than the numbers of IFN- $\gamma$ (median $=0 \%, p=0.004)$ and TNF- $\alpha$-expressing (median $=$ $18 \%, p=0.01)$ MGCs $(p<0.01)$, while numbers of TGF- $\beta$ expressing ECs were lower than TNF- $\alpha$ - (median $=59.5 \%$, $p<0.001)$ and IL-10-expressing (median $=47.9 \%, p=0.01$ ) ECs. The correlation between the numbers of ECs and MGCs expressing different proteins is shown in Table 1. The numbers of TGF- $\beta$-expressing ECs correlated positively with the numbers of IL-10- $(p<0.05)$ and TNF- $\alpha$-expressing $(p<0.001) \mathrm{ECs}$, while the numbers of TGF- $\beta$-expressing MGCs correlated positively with IFN- $\gamma$-expressing MGCs $(p<0.05)$. IL-10- and TNF- $\alpha$-expressing MGCs also correlated positively $(p<0.001)$.

\section{Discussion}

The differential expression of mycobacterial antigens, inflammatory and apoptosis markers by the ECs and MGCs suggests different functions of the two cell types. The ECs seem to have better mycobactericidal functions and consequently have lesser antigen load as determined by MPT64 expression. When these cells mature into MGCs, the expression of TGF- $\beta$ increases which can lead to reduced mycobactericidal capability. Consequently, these cells carry a higher antigen load than the ECs. This transition in the pattern of cytokine expression can be attributed to the interaction of $M$. tuberculosis with the host cells to avoid killing by the host cells.

Both ECs and MGCs expressed caspase 3, which suggest that these cells are removed by apoptosis. This is in agreement with the observations that activated immune cells are eliminated by apoptosis which limits their destructive potential. However, the number of apoptotic MGCs and the MGCs with MPT64 antigen were higher than the respective ECs. Based on these findings, it can be hypothesised that the ECs which contain mycobacterial antigens may avoid apoptosis and preferentially fuse to form MGCs, while those without mycobacteria or its components are removed by apoptosis. The negative correlation of MPT64-antigen-expressing MGCs with the apoptotic MGCs implies that those with the most antigens may resist apoptosis. This is in agreement with studies showing that virulent mycobacteria cause inhibition of 
Table 1 Relationship between the numbers of epithelioid cells and multinucleated giant cells expressing caspase 3, apoptosis-related proteins and various cytokines in granulomas caused by M. tuberculosis based on Spearman's rank correlation

\begin{tabular}{|c|c|c|c|c|c|c|c|c|c|c|c|c|c|}
\hline & \multicolumn{6}{|l|}{$\mathrm{EC}$} & \multicolumn{7}{|l|}{ MGC } \\
\hline & Fas & Bax & IL-10 & TNF- $\alpha$ & TGF- $\beta$ & IFN- $\gamma$ & FasL & Fas & Bax & IL-10 & TNF- $\alpha$ & TGF- $\beta$ & IFN- $\gamma$ \\
\hline \multicolumn{14}{|l|}{$E C$} \\
\hline FasL & $0.7^{*}$ & $0.59 * *$ & -0.25 & -0.17 & -0.06 & -0.30 & 0.24 & & & & & & \\
\hline Fas & & $0.58 * *$ & -0.30 & -0.37 & -0.35 & -0.31 & & $0.64 *$ & & & & & \\
\hline Bax & & & -0.13 & 0.08 & 0.17 & -0.07 & & & $0.85^{*}$ & & & & \\
\hline IL-10 & & & & 0.30 & $0.39 * *$ & 0.05 & & & & 0.16 & & & \\
\hline TNF- $\alpha$ & & & & & $0.67^{*}$ & 0.22 & & & & & -0.15 & & \\
\hline TGF- $\beta$ & & & & & 0.12 & & & & & & & 0.26 & \\
\hline IFN- $\gamma$ & & & & & & & & & & & & & 0.26 \\
\hline \multicolumn{14}{|l|}{$M G C$} \\
\hline FasL & & & & & & & & 0.38 & 0.22 & -0.02 & 0.15 & $0.55^{* *}$ & $0.57 * *$ \\
\hline Fas & & & & & & & & & 0.45 & $0.51^{* *}$ & 0.29 & 0.11 & -0.07 \\
\hline Bax & & & & & & & & & & 0.24 & 0.29 & 0.07 & 0.20 \\
\hline IL-10 & & & & & & & & & & & $0.68 *$ & 0.08 & -0.09 \\
\hline TNF- $\alpha$ & & & & & & & & & & & & 0.26 & 0.28 \\
\hline TGF- $\beta$ & & & & & & & & & & & & & $0.49 * *$ \\
\hline
\end{tabular}

The values shown are the correlation coefficients.

$* p<0.001 ; * * p<0.05$

apoptosis and use these cells as a sanctuary to avoid immune response and persist in the host [15, 20, 22]. These MGCs may then prevent the granulomas to regress and heal, by antigen presentation to the surrounding lymphocytes and continuous recruitment of new cells. These suggestions are supported by findings from a previous work where an in vitro model of granulomas showed that only virulent species of the $M$. tuberculosis complex triggered the formation of MGCs, resembling natural Langhans giant cells found in human tuberculous granulomas [17]. These large MGCs are as active as macrophages, but they have reduced capacity of phagocytosis, despite a conserved ability to mediate antigen presentation.

Antigen-presenting cells with increased expression of FasL are shown to induce apoptosis in T-cells during antigen presentation, thus inducing antigen-specific T-cell tolerance [35]. In this study, more MGCs expressed FasL than ECs, and FasL-expressing MGCs correlated positively with TGF- $\beta$-expressing MGCs. As the infected MGCs are shown to possess antigen presentation capability by expression of major histocompatibility complex class II receptors [17], it can be assumed that FasL-expressing MGCs may lead to death of a subset of M. tuberculosisspecific T-cells, causing specific immune suppression in the host. This hypothesis is indirectly supported by studies in tuberculosis patients where constant apoptosis of T-cells has been shown to result in a reduction in T-cell numbers and depressed proliferative responses [14, 18]. Furthermore, the observation that FasL-expressing ECs correlate positively with Fas-expressing ECs while no significant correlation was found between these proteins among MGCs suggests that MGCs with increased expression of FasL do not simultaneously express Fas, which would help these cells to evade being killed via Fas-FasL pathway.

MPT64 is a 26-KD secreted mycobacterial protein shown to be specific for $M$. tuberculosis complex organisms [6, 12]. Secreted mycobacterial proteins are considered immunodominant and are involved in inducing protective immunity [1], but little is known about the role of MPT64 in host immunity. This antigen has been detected in the macrophages of human and mouse TB lesions [26, 27] and elicits T-cell responses in patients infected with TB [29]. The region encoding the corresponding mpb64 gene is deleted from several bacillus Calmette-Guerin strains, and this has been correlated with a drop in virulence in animal infection models and reduced vaccine lesions in humans [2], suggesting a role of MPT64 in mycobacterial virulence. In this study, increased expression of MPT64 and TGF- $\beta$, FasL and Fas in MGCs as compared to ECs and a negative correlation between MPT64 expression and apoptosis in MGCs suggests that MPT64 may induce an increased expression of these proteins and inhibition of apoptosis of infected MGCs, making them more suitable for mycobacterial survival. There was, however, no significant correlation between MGCs expressing MPT64 and these proteins, and further studies are required to investigate the role of MPT64 in disease pathogenesis.

The difference in the pattern of relationship of cytokines between ECs and MGCs suggests different roles of these two cell types for control of the infection. Paradoxically, the number of MGCs expressing anti-inflammatory cytokines TGF- $\beta$ and IL-10 correlated positively with MGCs 
expressing pro-inflammatory cytokines IFN- $\gamma$ and TNF- $\alpha$, respectively. However, the intensity of staining for IFN $-\gamma$ was less than TGF- $\beta$ in MGCs as shown in Fig. 2, which may imply a reduced amount of IFN- $\gamma$ as compared to TGF- $\beta$ in these cells, while this difference in intensity was not reflected in the cell counts. Furthermore, TGF- $\beta$ can block the mycobactericidal mechanisms induced by IFN- $\gamma$ [33], and IL-10 has been shown to block the activity of TNF- $\alpha$ by inducing the release of soluble TNF- $\alpha$ receptor type 2 (TNFR2) from macrophages and the formation of inactive TNF- $\alpha$-TNFR2 complexes [10]. These observations suggest that MGCs by virtue of increased levels of antiinflammatory cytokines favour mycobacterial persistence.

In conclusion, we have found that a higher number of MGCs contain M. tuberculosis secretory antigen MPT64 and express more TGF- $\beta$ as compared to ECs, implying that the maturation of ECs into MGCs is associated with reduction in mycobactericidal function which can lead to accumulation of mycobacterial antigen. The negative correlation between MPT64 in MGCs and caspase-3-expressing MGCs suggests that the infected MGCs avoid apoptosis. The MGCs and ECs may thus play different roles, EC being more fit to eliminate the bacilli, while MGCs harbour them. The relationship between these cells needs further analysis.

Acknowledgements We thank Dr. Sayoki G. Mfinanagi at the National Institute for Medical Research, Muhimbili Research Station, Tanzania for the provision of biopsies from Tanzania. This study was supported by funds from the University of Bergen, from Norwegian health-related research funding agency; Helse-Vest and Norwegian trusts for research funding; Gades Legat, Connie Gulberg Jansens Legat, and Skipsreder Tom Wilhelmsens Stiftelse.

Conflict of interest statement We declare that we have no conflict of interest.

Open Access This article is distributed under the terms of the Creative Commons Attribution Noncommercial License which permits any noncommercial use, distribution, and reproduction in any medium, provided the original author(s) and source are credited.

\section{References}

1. Andersen P (1997) Host responses and antigens involved in protective immunity to Mycobacterium tuberculosis. Scand J Immunol 45:115-131

2. Behr MA, Wilson MA, Gill WP, Salamon H, Schoolnik GK, Rane S, Small PM (1999) Comparative genomics of BCG vaccines by whole-genome DNA microarray. Science 284:1520-1523

3. Casanova JL (2000) Mendelian susceptibility to mycobacterial infection in man. Bull Acad Natl Med 184:1409-1416

4. Chantry D, Turner M, Abney E, Feldmann M (1989) Modulation of cytokine production by transforming growth factor-beta. J Immunol 142:4295-300

5. Cooper AM, Dalton DK, Stewart TA, Griffin JP, Russell DG, Orme IM (1993) Disseminated tuberculosis in interferon-gamma gene-disrupted mice. J Exp Med 178:2243-2247
6. Elhay MJ, Oettinger T, Andersen P (1998) Delayed-type hypersensitivity responses to ESAT-6 and MPT64 from Mycobacterium tuberculosis in the guinea pig. Infect Immun 66:34543456

7. Emile JF, Patey N, Altare F, Lamhamedi S, Jouanguy E, Boman F, Quillard J, LecomteHoucke M, Verola O, Mousnier JF, Dijoud F, Blanche S, Fischer A, Brousse N, Casanova JL (1997) Correlation of granuloma structure with clinical outcome defines two types of idiopathic disseminated BCG infection. J Pathol 181:25-30

8. Flesch IE, Kaufmann SH (1990) Activation of tuberculostatic macrophage functions by gamma interferon, interleukin-4, and tumor necrosis factor. Infect Immun 58:2675-2677

9. Flynn JL, Goldstein MM, Chan J, Triebold KJ, Pfeffer K, Lowenstein CJ, Schreiber R, Mak TW, Bloom BR (1995) Tumor necrosis factor-alpha is required in the protective immune response against Mycobacterium tuberculosis in mice. Immunity 2:561-572

10. Fratazzi C, Arbeit RD, Carini C, Balcewicz-Sablinska MK, Keane J, Kornfeld H, Remold HG (1999) Macrophage apoptosis in mycobacterial infections. J Leukoc Biol 66:763-4

11. Gasser A, Most J (1999) Generation of multinucleated giant cells in vitro by culture of human monocytes with Mycobacterium bovis $\mathrm{BCG}$ in combination with cytokine-containing supernatants. Infect Immun 67:395-402

12. Harboe M, Nagai S, Patarroyo ME, Torres ML, Ramirez C, Cruz N (1986) Properties of proteins MPB64, MPB70, and MPB80 of Mycobacterium bovis BCG. Infect Immun 52:293-302

13. Hernandez-Pando R, Orozco H, Arriaga K, Sampieri A, LarrivaSahd J, Madrid-Marina V (1997) Analysis of the local kinetics and localization of interleukin-1 alpha, tumour necrosis factoralpha and transforming growth factor-beta, during the course of experimental pulmonary tuberculosis. Immunology 90:607-617

14. Hirsch CS, Toossi Z, Vanham G, Johnson JL, Peters P, Okwera A, Mugerwa R, Mugyenyi P, Ellner JJ (1999) Apoptosis and T cell hyporesponsiveness in pulmonary tuberculosis. J Infect Dis 179:945-953

15. Keane J, Remold HG, Kornfeld H (2000) Virulent Mycobacterium tuberculosis strains evade apoptosis of infected alveolar macrophages. J Immunol 164:2016-2020

16. Kindler V, Sappino AP, Grau GE, Piguet PF, Vassalli P (1989) The inducing role of tumor necrosis factor in the development of bactericidal granulomas during BCG infection. Cell 56:731-740

17. Lay G, Poquet Y, Salek-Peyron P, Puissegur MP, Botanch C, Bon H, Levillain F, Duteyrat JL, Emile JF, Altare F (2007) Langhans giant cells from M-tuberculosis-induced human granulomas cannot mediate mycobacterial uptake. J Pathol 211:76-85

18. Manfredi AA, Heltai S, Rovere P, Sciorati C, Paolucci C, Galati G, Rugarli C, Vaiani R, Clementi E, Ferrarini M (1998) Mycobacterium tuberculosis exploits the CD95/CD95 ligand system of gammadelta T cells to cause apoptosis. Eur J Immunol 28:1798-1806

19. Mfinanga SG, Morkve O, Kazwala R, Cleaveland S, Sharp M, Kunda J, Nilsen R (2004) Mycobacterial adenitis: role of Mycobacterium bovis, non-tuberculous mycobacteria, HIV infection, and risk factors in Arusha, Tanzania. East Afr Med J 81:171-178

20. Mogga SJ, Mustafa T, Sviland L, Nilsen R (2002) Increased Bcl-2 and reduced Bax expression in infected macrophages in slowly progressive primary murine Mycobacterium tuberculosis infection. Scand J Immunol 56:383-391

21. Murray PJ, Wang L, Onufryk C, Tepper RI, Young RA (1997) T cell-derived IL-10 antagonizes macrophage function in mycobacterial infection. J Immunol 158:315-21

22. Mustafa T, Phyu S, Nilsen R, Bjune GRJ (1999) Increased expression of Fas ligand on Mycobacterium tuberculosis infected macrophages: a potential novel mechanism of immune evasion by Mycobacterium tuberculosis? Inflammation 23:507-521 
23. Mustafa T, Bjune TG, Jonsson R, Pando RH, Nilsen R (2001) Increased expression of fas ligand in human tuberculosis and leprosy lesions: a potential novel mechanism of immune evasion in mycobacterial infection. Scand J Immunol 54:630-9

24. Mustafa T, Mogga SJ, Mfinanga SGM, Mørkve O, Sviland L (2005) Significance of Fas and Fas Ligand in tuberculous lymphadenitis. Immunology 114:255-262

25. Mustafa T, Mogga SJ, Mfinanga SGM, Morkve O, Sviland L (2006) Immunohistochemical analysis of cytokines and apoptosis in tuberculous lymphadenitis. Immunology 117:454-462

26. Mustafa T, Phyu S, Nilsen R, Jonsson R, Bjune G (1999) A mouse model for slowly progressive primary tuberculosis. Scand $\mathrm{J}$ Immunol 50:127-136

27. Mustafa T, Wiker HG, Mfinanga SGM, Morkve O, Sviland L (2006) Immunohistochemistry using a Mycobacterium tuberculosis complex specific antibody for improved diagnosis of tuberculous lymphadenitis. Mod Pathol 19:1606-1614

28. Mustafa T, Wiker HG, Morkve O, Sviland L (2007) Reduced apoptosis and increased inflammatory cytokines in granulomas caused by tuberculous compared to non-tuberculous mycobacteria: role of MPT64 antigen in apoptosis and immune response. Clin Exp Immunol 150:105-113

29. Roche PW, Triccas JA, Avery DT, Fifis T, Billmanjacobe H, Britton WJ (1994) Differential T-cell responses to mycobacteriasecreted proteins distinguish vaccination with Bacille Calmette-
Guerin from infection with Mycobacterium tuberculosis. J Infect Dis $170: 1326-1330$

30. Sandor M, Weinstock JV, Wynn TA (2003) Granulomas in schistosome and mycobacterial infections: a model of local immune responses. Trends Immunol 24:44-52

31. Saunders BM, Frank AA, Orme IM (1999) Granuloma formation is required to contain bacillus growth and delay mortality in mice chronically infected with Mycobacterium tuberculosis. Immunology 98:324-328

32. Takashima T, Ohnishi K, Tsuyuguchi I, Kishimoto S (1993) Differential regulation of formation of multinucleated giant-cells from concanavalin-A-stimulated human blood monocytes by IfnGamma and Il-4. J Immunol 150:3002-3010

33. Toossi Z, Ellner JJ (1998) The role of TGF beta in the pathogenesis of human tuberculosis. Clin Immunol Immunopathol $87: 107-114$

34. Toossi Z, Gogate P, Shiratsuchi H, Young T, Ellner JJ (1995) Enhanced production of TGF-beta by blood monocytes from patients with active tuberculosis and presence of TGF-beta in tuberculous granulomatous lung lesions. J Immunol 154:465473

35. Zhang HG, Su X, Liu D, Liu W, Yang P, Wang Z, Edwards CK, Bluethmann H, Mountz JD, Zhou T (1999) Induction of specific T cell tolerance by Fas ligand-expressing antigen-presenting cells. J Immunol 162:1423-1430 